\title{
CENTRAL DIABETES INSIPIDUS AND ITS MANAGEMENT WITH ORAL ANTIDIURETIC AGENTS
}

by Shahid Athar, M.D.D. and Gary Roberıson. M.D.* Department of Medicine and Edocrinology, St. Vincent Hospital, Indianapolis, Indiana and Indiana University School of Medicine. Indianapolis. Indiana

Dr. Shahid Athar is currenily Assistant Clinical Professor of Medicine at Indiana University School of Medicine. He is also Director of Section of Endocrinology and Medical Director of Metabolic Unit at St. Vincent Medical Center in Indianapolis. Indiana.

- Present Address: Deparment of Endocrinology. Billing's Hospital. Universizy of Chicago. Chicago. Illinois.

Artinine Vasopressin (AVP) the main antidiuretic hormone is secreted by supraoptic nucleus of the hypothalmus and transported to the posterior pituitary for the purpose of storage and released via hypothalmic hypophysical tract. Vasopressin exerts its main action i.e. conservation of water at distal renal tubule by enhancing the reabsorption of free water. It is postulated that this action is mediated through cyclic AMP system.

With the development of a sensitive radioimmunoassay measurement of vasopressin in blood, we have defined the factors controiling $\mathrm{ADH}$ release (ref. 1-3). The OSMO receptors are sensitive to scrum osmolatity which is mainly due to serum sodium. Rise in serum osmolality due to the infusion of hypertonic saline will incrcase AVP secretion. Other extra cellular solutes like mannitol and urea also have similar effect. Glucose, being both an extra and intra cellular ion has a paradoxical effect (Fig. I).

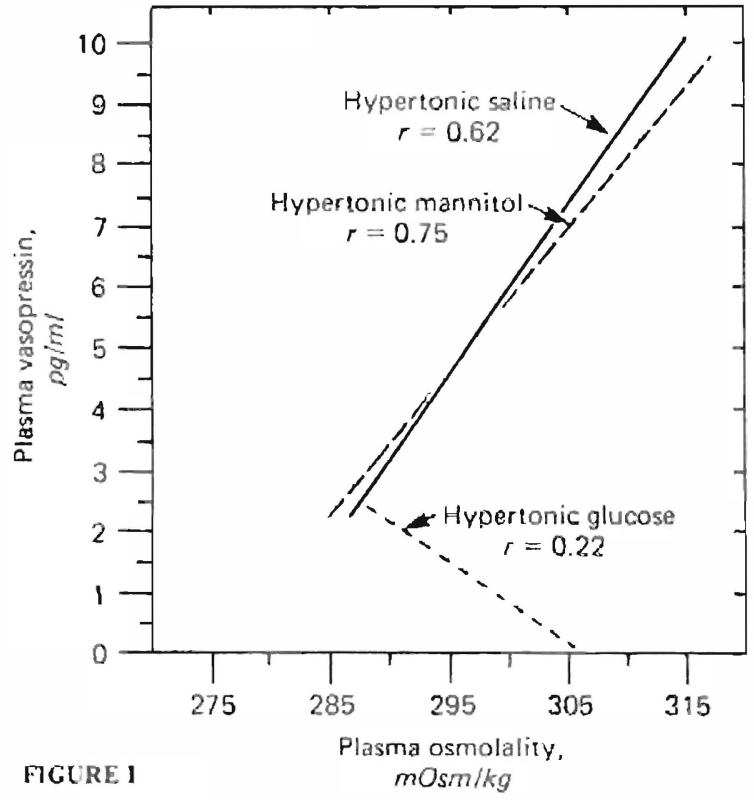

AVP secretion is stimulated by Hypovolemia (due to dehydration or hemorrhage). hypotension (postural or drug induced), nicotin and angiotension II. ADH release is inhibited by hypoosmolality due to ECV expansion by watcr ingestion $(29 \mathrm{ml} / \mathrm{kg} \mathrm{BW})$. Alcohol and dilantin also

DOI: http://dx.doi.org/10.5915/13-3-11962 have been reported to have a central inhibiting effect. Drugs like lithium and chlortetryacycline do not have effect on ADH release but poison adenyl cyclase in the distal renal tubule which is needed for the action of ADH through cyclic AMP system.

When a patient with symptoms of excessive thirst presents, the cause of polydipsia duc to polyuria could be in the hypothalmic-pituitary damage (central diabetes insipidus) or reduced ADH response to renal tubules (nephrogenic DIL). Osmodiuresis (diabetes mellitus) or psychogenic (compulsive water drinking). Pathophysiology and differential diagnosis of three forms of polyuria are shown in Fig. 2 and 3.

The central diabetes insipidus is also of 4 types depending on the severity of the lesion leading to complete DI (Type I) to partial (Type 2. 3) and near normal or subnormal urine coneentration (Type 4). Clinical clues in history especially that of head injury and granolomatous infection are helpful. Nearly $60 \%$ of central DI is now as result of either surgery or injury in the hypothalmic-pituitary area, $30 \%$ due idiopathic reasons and $10 \%$ due to various CNS infections. Patients with psychogenic polydipsia usually do not have abrupt onset of DI. nor do they have nocturnal polyuria.

A reasonablc workup for polyurea-polydipsia syndrome should include careful daily intake output record for several days, serum electrolytes, blood glucose, urine specific gravity, serum and plasma osmolality at the same time and fluid restriction test. Hypertonic saline infusion and response to pitressin test should be done carefully and under close supervision. Depending upon above test and clinical history, and anterior pituitary investigation, sella $x$ rays with tomogram and $C T$. scan of pituitary with air contrast is suggested. On the other hand if the diagnosis leads toward nephrogenic DI then careful cvaluation of renal [unction and detail drug history is advised. For compulsive water drinking psychologica! evaluation may be helpiul.

Patients with central DI are unable to concentrate their urine depending on the amount of ADH available. Therefore their urine osmolality will be low for a given plasma osmolality and plasma AVP $(A D H)$ will be low (sec Fig. 4-5). On the other hand

The Journal of IMA-Vol. 13-July 1981-Page 91 
Pituitary Diabetes Insipidus

Deficient ADH Secretion

Deficient urinary concentration

Large volumes urine (polyuria) 1

Deficit body water

Plasma hyperosmolality

Thirst (polydipsia)

Increased water intake (polydipsia) Increased water intake (polydipsia)

Increased water intake (polydipsia) Increased water intake (polydipsia) -
Thirst (polydips
FIGURE 2

Primary Polydipsia

Excessive water intake (polydipsia)

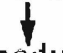

Excess body water

Plasma hypo osmolality

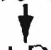

Suppression ADH, Secretion

Deficit body water

Plasma hyperosmolality
Deficient urinary concentration

L.arge volumes urine (polyuria)

\section{POLYURIA-DIFFERENTIAL DIAGNOSIS}

Plasma Osmolality

Basal

Normal

Diabeles Insipidus

Pituitary

Diabetes Insipidus

Nephrogenic

Primary Polydipsia
282-294*

Normal or High

Normal or HIgh

Normal or Low:

${ }^{*} \mathrm{mOsm} / \mathrm{Kg}$
Urine Osmolality

Basal

Dehydration

Pitressin

$600-1100 *$

Low

$900-1300^{*}$

$600-900 *$

Low

Normal

Low

Low

Low

Low

Low-Normal

Low-Norma]

FIGURE 3

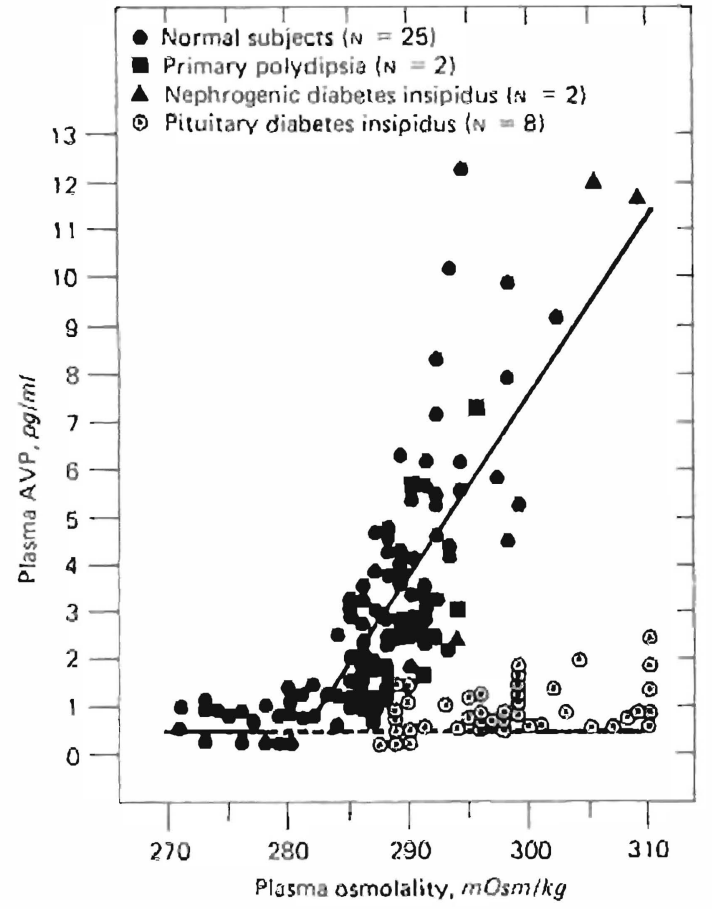

FIGURE 4
- Normal subjects $(\mathrm{N}=23)$

- Primary polydipsia $(N=2)$

$\Delta$ Nephrogenic diabetes insipious $(N=2)$

- Pituitary diabetes insipidus $(\mathrm{N}=8)$

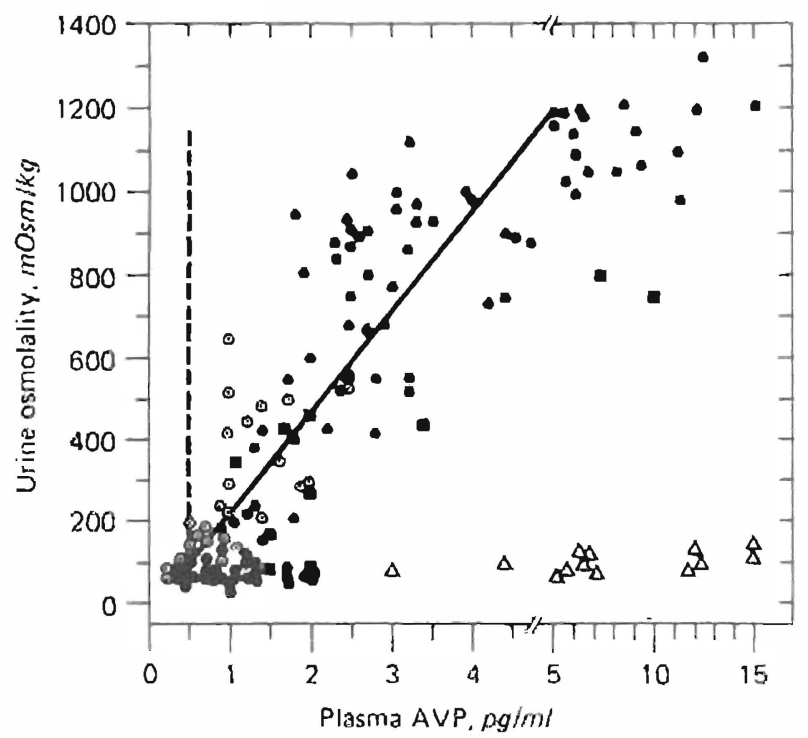

FIGURES 
patients with psychogenic polydipsia will have low POSM due to expansion of ECV. After $8-12$ hours of Chuid restriction normal individuals and those with psychogenic polydipsia will increase urine osmolality to minum of $800 \mathrm{M}$ OSM. Patients with central DI will have varying degrees of subconcentration depending on the amount of ADH available. Response to pitressin will distinguish between nephogenic DI and central DI.

Polyurea should be managed according to its etiology. For central diabetes insipidus this is pitressin by injection or nasal spray, and oral antidiuretic agents. Pitressin injection has unpredictable response and frequently leads to hyponatremia if over used. Synthetic vasopressin nasal spray is tolerated much better, however, it is poorly asorbed by patient with nasal allergy and mucosal edema. Both forms may be cardiac vasoconstrictive and also may lead to antibody formation leading to decreased effectiveness.

Oral antidiuretic agents are not only more effective and convenient (easy) to administer but also have less side effects. They include clofibrate, chlorpropamide and carbamazepine. None of them is effective in lowering urine output in normal persons, nephrogenic DIL, psychogenic polydipsia or complete (Type I) DI (no $A D H$ ). Addition of thiazide diuretic, reduces urine output by producing negative sodium balance GFR. We are in the process of reporting our experience with 30 patients with central DI on oral antidiuretic agents. Here we present data on 3 such patients as preliminary report. Two of these patients had idiopathic DI. and one post hy'pophysectomy DI. Their fluid intake, urine output, urine and plasma osmolality are shown in Table 6, 7, 8. Plasma AVP was measured by radioimmunoassay as described earlier (ref. I).

We conclude that, both clolibrate in dose of 2-3 $\mathrm{GM} /$ day and chlorpropamide in dose of $500 \mathrm{MG}$; day are effective in lowering urine output from $50-80 \%$. Clofibrate alone is less elfective than chlorpropamide. however. when either of them was combined with chlorthiaside $500 \mathrm{MG}$ daily, there was further reduction in urine output. By 3 rd-4th day of the combined treatment metabolic balance was achieved.

There was appropriate increase in urine osmolality. Plasma osmolality fell to normal suggesting that the anti diuretic effect of these agents was not due to

\section{PATIENT 1, TABLE 6}

\section{TREATMENT OF PITUITARY DIABETES INSIPIDUS WITH ORAL AGENTS}

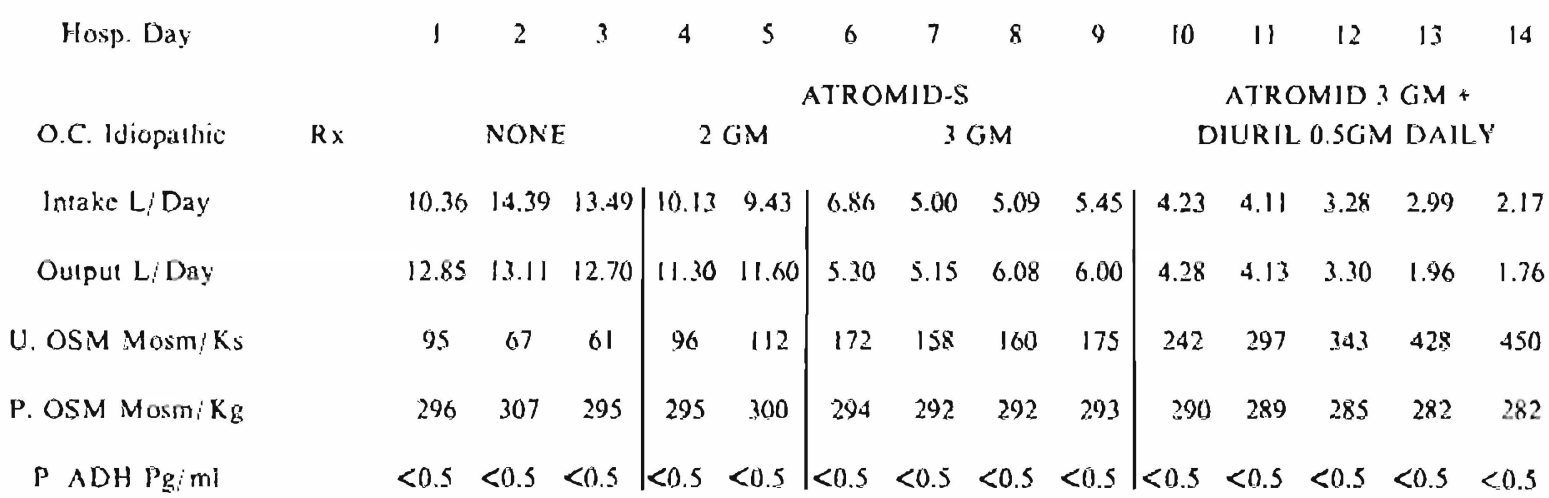

PATIENT 2, TABLE 7

TREATMENT OF PITUITARY DIABETES INSIPIDUS WITH ORAL AGENTS

\begin{tabular}{|c|c|c|c|c|c|c|c|c|c|c|c|c|c|c|}
\hline Hosp. Day & 1 & 2 & 3 & 4 & $\varsigma$ & 6 & 7 & 8 & 9 & 10 & 11 & 12 & 13 & 14 \\
\hline $\begin{array}{l}\text { M.C. Post } \\
\text { Hypo }\end{array}$ & & NO & & & \multicolumn{4}{|c|}{$\begin{array}{l}\text { DIABINESE } 500 \mathrm{MG} \\
\text { DAILY }\end{array}$} & & NE & \multicolumn{4}{|c|}{$\begin{array}{c}\text { CLOFIBRATE } 2 \\
\text { GM/DAY (Alromid-s) }\end{array}$} \\
\hline Fluid Intake L/ Day & 4.08 & 5.24 & 3.93 & 5.05 & 3.95 & 2.10 & 2.31 & 1.75 & 4.05 & 4.44 & 2.90 & 2.78 & 2.71 & 2.70 \\
\hline Urine Output L/Day & 5.15 & 5.36 & 5.14 & 5.28 & 3.88 & 2.90 & 1.94 & 1.78 & 3.51 & 3.35 & 1.71 & 1.69 & 1.98 & 2.00 \\
\hline U. OSM Mogm $\mathrm{Kg}$ & 176 & 167 & 152 & 156 & 221 & 263 & 3.35 & 407 & 195 & 203 & 376 & 370 & 36.5 & 543 \\
\hline P. OSM Mosm/ Kg & 30.3 & 296 & 297 & 299 & - & 295 & 293 & 291 & 302 & 302 & 300 & 298 & 296 & 294 \\
\hline P. ADH $\mathrm{Pg} / \mathrm{MI}$ & 0.5 & 0.5 & 0.5 & 0.5 & - & 0.5 & 0.5 & 0.5 & 0.5 & 0.5 & 0.5 & 0.5 & 0.5 & 0.5 \\
\hline
\end{tabular}




\section{PATIENT 3 FIGURE 8}

\section{TREATMENT OF PITUITARY DIABETES INSIPIDUS WITH ORAL AGENTS}

Hosp. Day

J.N. Idiopathic

Inlake L/Day

Output L/Day

U. OSM Mosm/ $\mathrm{Kg}$

P. OSM Posm $\mathrm{Kg}$

P. ADH Pg/ml.
$\mathrm{Rx}$

\begin{tabular}{ccc|c}
\multicolumn{3}{c}{ NONE } \\
9.58 & 9.20 & 8.50 \\
8.35 & 8.80 & 7.80 \\
96 & 80 & 86 \\
316 & 308 & 310 \\
0.6 & 0.7 & 0.5
\end{tabular}
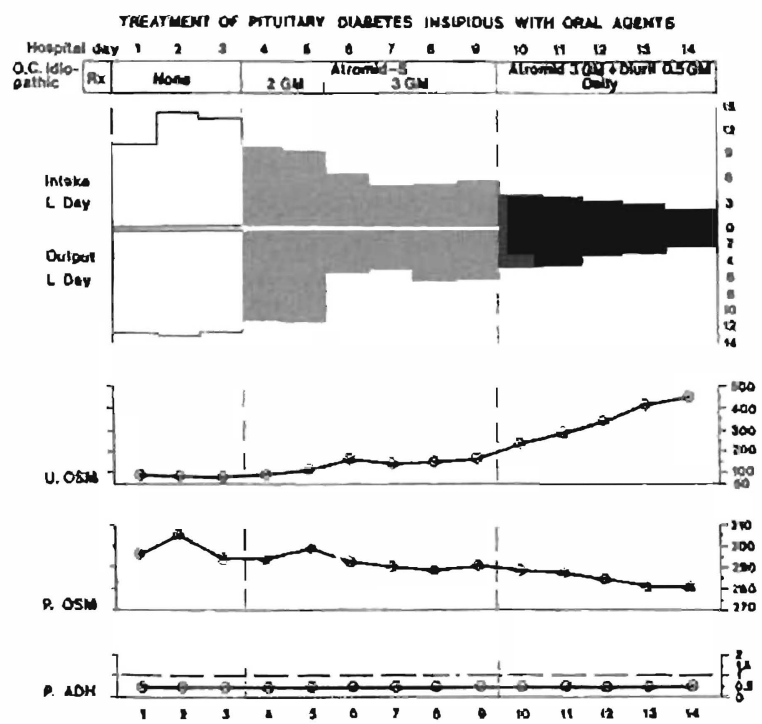

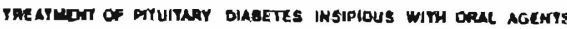

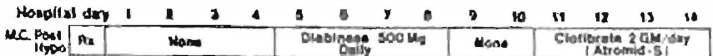

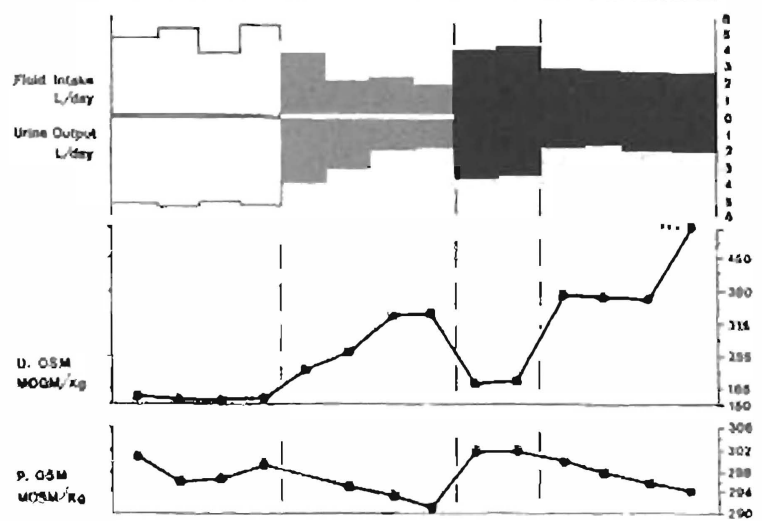

P. $20+1$

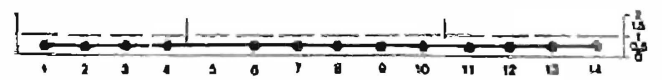

ATROMID 3 GM/DAY ATROMID $3 \mathrm{GM}+$ DIURIL $0.5 \mathrm{GM}$

\begin{tabular}{lllll|llllll}
7.82 & 6.44 & 6.40 & 5.60 & 5.12 & 4.26 & 3.80 & 3.65 & 3.00 & 2.80 & 2.10 \\
6.90 & 6.15 & 5.80 & 5.20 & 4.60 & 4.10 & 3.40 & 3.30 & 3.10 & 2.60 & 2.00 \\
120 & 191 & 154 & 260 & 258 & 270 & 284 & 350 & 410 & 474 & 2590 \\
308 & 307 & 305 & 303 & 300 & 298 & 296 & 295 & 293 & 290 & 288 \\
0.8 & 0.9 & 0.7 & 0.5 & 0.6 & 0.5 & 0.5 & 0.6 & 0.5 & 0.5 & $0 \mathrm{~J}$
\end{tabular}

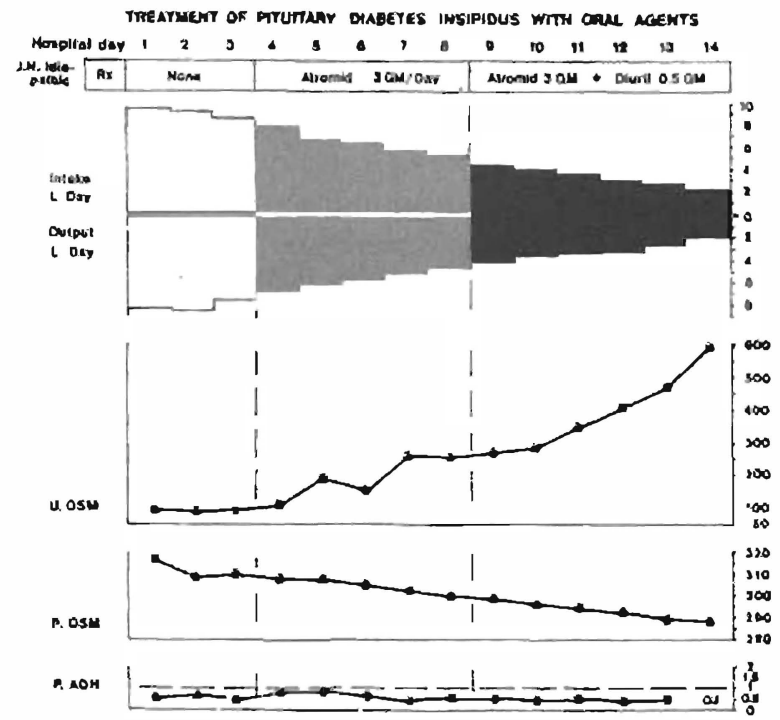

increase in AVP secretion but rather on the renal tubular level. This was confirmed by AVP level measured by radioimmunoassay which was low in these patients with central DI before and did not increase after treatment with oral agents. We recommended clofibrate 2 to $3 \mathrm{GM}$ with chlorthiazide $500 \mathrm{MG}$. daily in the management of central diabetes insipidus. We noted no side effects of clofibrate: however patients with thiazide diuretics should be observed and treated for hypokalemia.

We thank our secretary Betly McAninch for typing this manuscript.

Requests for reprints should be addressed to Doctor Shahid Athar, 8402 Harcourt Road. Suite 509. Indianapolis, Indiana 46260.

Dr. Shahid Athar is currently Assistant Clinical Professor of Medicine at Indiana University School of Medicine. He is also Director of Section of Endocrinology and Medical Director of Metabolic Unit at St. Vincent Medical Center in Indianapolis. Indiana. 


\section{REFERENCES}

I. Robertson, G.L.. Mohr, E.A.. Athar, S. and Sinaha. T. 1973. The Development and Clinical Application of a New Method for the Radioimmunoassay of Argentine Vasopressin in Human Plasma, J. Clin. Invest. 52:2340-2352.

2. Robertson, G.L., Shelton, R.L.. Athar, S. 1976. The Osmoregulation of Vasopressin in Kidney International Volume 10 (1976), p. 25-37.

3. Robertson, G.L., Athar, S., 1976. The Interaction of Blood Osmolality and Plasma Volume in Regulation Plasma Vasopressin in Man. J. Clinc Endocrinology META 42:613-1976.
4. Moses, A.M., 1977. Diabetes Insipid us and ADH Regulation Hospital Practice July 77, p. 37-44.

5. Coggin. C.H. and Leaf 1967. Diabetes Insipidus Am. J. Medicine 42:807-813.

6. Rado, J.P. Combination of Carbamazepine Hyperoresponder Pituitary Diabetes Insipidus J. Cline Endocrinology MET 38:1. 1974.

7. Moses, A.M., et al. 1973. Clofibrate Antidiuretics, J. Cline Investigation Vol. 52 March 1973, p. 535-541.

8. Hannulth, Y. and Gelb. A.M. Clofibrate Treatment of Idiopathic Diabetes Insipidus. JAMA May 14. 1973 (A letter). 